\title{
Moodle: Teaching Strategies in Distance Education in Oral Medicine
}

\author{
Rubens Cardozo de Castro Junior, ${ }^{1}$ Tuana Caruso Medeiros, ${ }^{1}$ Heitor Marques Honório, ${ }^{2}$ \\ Eduardo Sant'Ana, ${ }^{1}$ and Paulo Sérgio da Silva Santos ${ }^{1}$ \\ ${ }^{1}$ Department of Oral Biology and Stomatology, Bauru School of Dentistry, Bauru, SP, Brazil \\ ${ }^{2}$ Department of Pediatric Dentistry, Orthodontics and Public Health, Bauru School of Dentistry, Bauru, SP, Brazil
}

Correspondence should be addressed to Paulo Sérgio da Silva Santos; paulosss@usp.br

Received 21 December 2016; Revised 21 March 2017; Accepted 1 June 2017; Published 5 July 2017

Academic Editor: Izzet Yavuz

\begin{abstract}
Copyright (C) 2017 Rubens Cardozo de Castro Junior et al. This is an open access article distributed under the Creative Commons Attribution License, which permits unrestricted use, distribution, and reproduction in any medium, provided the original work is properly cited.
\end{abstract}

\begin{abstract}
Objective. The current model of education has been suffering changes, undergoing renovations, and seeking using and enjoying increasingly technological resources, as, for example, the Learning Management System (LMS). One of the most used LMS platforms is the Modular Object Oriented Dynamic Learning Environment (Moodle). This article proposes to demonstrate how Moodle platform was introduced in the subject of Stomatology through a clear and objective methodology. Study Design. In six months, 49 undergraduate students enrolled in stomatology subject accessed Moodle platform 2067 times and performed 02 evaluation exams at Discipline of Stomatology. Statistical analysis was performed by paired $t$-test (comparison between number of access times before the first evaluation and number of access times before the second evaluation), Wilcoxon test (student's grade on the first and second evaluation), and Pearson correlation test (correlation between the number of access times before the first evaluation and the first grade, correlation between the number of access times before the second evaluation and the second grade, and correlation between the variation of the number of access times and the variation of the student's grade). Results and Conclusion. The digital platform Moodle was associated with better grade for those students who access it for more times $(p<0,001)$ and was able to supply the needs of the students and help them to obtain information about the subject during the entire semester (6 months).
\end{abstract}

\section{Introduction}

Web-based virtual learning environments (VLEs) are a set of teaching and learning tools designed to enhance a student's learning experience by including computers and the Internet in the learning process and are used in many medical schools $[1,2]$. The current model of education has been suffering changes, undergoing renovations, and increasingly harnessing the benefits of technological resources, as, for example, the Learning Management System (LMS). One of the most used LMS platforms is the Modular Object Oriented Dynamic Learning Environment (Moodle) [3]. This virtual environment aims to enhance the learning experience through virtual lessons, scientific articles texts, questions and answers, quizzes, and class lessons [3].
The access at the moment of processing information allows stakeholders to have greater flexibility to study (synchronic model). It is in this context the virtual learning environments (VLE) come up. New educational opportunities were offered where teaching conditions, both those developed at a distance and those carried out in classroom teaching, ensured and amplified the actions of this type of educational practice $[3,4]$.

Currently, Moodle has been increasingly improved and it is possible constantly update and apply functions that meet a wide range of users; in addition, there is the possibility of applying different teaching practices $[3,4]$.

Undergraduate students in dentistry have shown difficulties in learning stomatology due to various pathologies that affect the stomatognathic system; some of these have clinical, 
radiographic, and histological very similar appearances, which confuses the student [5].

Also considering that the students' current needs are changing with respect to the past $[6,7]$, the Internet can act as a powerful tool in improving the teaching and learning process in stomatology for dental courses; it relates to many of the difficult points mentioned above because it motivates the student to study, considering their possible limitations [6-8] This occurs because the Internet relieves the learning of the time factor, as, contrary to the classroom, when working on the computer, the student has the time that he or she deems necessary to see and review topics until he or she has reached the desired learning level $[8,9]$. Thus, it was found that there is no provision of websites and tutorials specific to the teaching of stomatology in Portuguese.

It was in this context that the Moodle platform was implemented on the Department of Stomatology, Bauru School of Dentistry, University of São Paulo $[3,4,10]$. Therefore, the aim of this study was to evaluate Moodle's effectiveness in students' learning of stomatology content for undergraduate dental students of a Brazilian university.

\section{Materials and Methods}

2.1. Study Design. The 2 study factors of this work were the statistical content assimilation by dental academics in stomatology which was evaluated by the grades in the first and second test and number of access times on Moodle in two stages and the final average with the total number of access times to the Moodle of a graduating class.

\section{T1: 49 students who did Test 1.}

T2: 49 students who did Test 2.

Moodle T1: 2017 Moodle access times before Test 1.

Moodle T2: 757 Moodle access times before Test 2 .

2.2. Development of Educational Material. For this research development, we created an educational material with an Internet interface. This educational material consisted of a proposed offer to the target audience of an online source for queries in stomatology.

The visual identity creation and interface design for the web, programming of the site in Flash, domain registration, hosting, infrastructure setup (dynamic language, database, email, and FTP - File Transport Protocol), publishing content system development, and technical support were all executed by a development company for web pages.

Professor of the Stomatology department created the following topics and the teaching assistants postgraduate students performed a digital material (videos, PowerPoint presentations, and summaries) using cases from the own department. The topics were Stomatology Introduction, Medical History, Vital Signs, Physical Examination, Salivary Gland Semiology, Lymph nodes Palpation, Temporomandibular Joint and Chewing Muscles Examination, Tooth Injuries, Tongue Diseases, and Oral Cavity Lesions. The content was added to the course website piece by piece.
2.3. Digital Platform. In order to make use of a virtual room, the students must be properly enrolled in the subject of the Department of Stomatology, Bauru School of Dentistry, University of São Paulo (FOB-USP). Through the Intranet (Moodle platform), they access the lesson held in the classroom and get educational materials to study outside of class time and it is also possible to exercise through questionnaires and quizzes as well as performed exams on exams proposed by the professors of the Department of Stomatology.

Each access was then registered, and, through the University Server, at the end of each semester, professors could count the number of access times performed by each student and, thus, ascertain whether there was a correlation between the highest number of access times on the Moodle platform and the better academic performance, measured by their tests grade.

2.4. Learning Evaluation. The assessment of learning was done through the evaluations regularly applied during the course of the discipline to evaluate the frequency of access to the Moodle platform of the students. There were theoretical and practical classes and seminars. The practices are divided into radiographic interpretation classes of digital and analog images focused on the craniofacial anatomy. The mucosal diseases practices will be held on computers with the clinical department or atlas collection images. Clinical practice sessions will be held with clinical examinations of patients, biopsies, radiographic techniques with emphasis on panoramic radiographs, and other complementary exams. Theoretical tests and theoretical-practical, descriptive or in the form of tests, where students exercise their diagnostic capability based on clinical history and patient's clinical picture, were designed on multimedia. During the current semester, each student performed 2 theoretical tests (weight $8,80 \%$ of rating) and 1 seminar clinical case (weight 2, 20\% of rating). These theoretical tests include essay questions and multiple-choice questions, in addition to practical activities that are exercises applied after certain lectures. After the end of the semester, each student received an arithmetic mean for their 2 theoretical tests and also for clinical practical activities and received a calculated final weighted mean, which considered the weight of each evaluation type.

The evaluation method was through tests and presentation of clinical cases seminar during the semester. The value of the grades ranges from 0 (zero for lowest score) and 10 (ten for highest score), assigning the final mark of all tests with an average of 5 .

2.5. Statistical Analysis. The data were analyzed by processing on the statistical program (SigmaPlot 12.0), applying normality test (Shapiro-Wilk), paired $t$-test, or Wilcoxon and Pearson correlation test. Significance level was set at $5 \%$.

\section{Results}

In six months, 49 students enrolled in stomatology subject accessed Moodle platform 2067 times at Bauru School of Dentistry, University of São Paulo. 


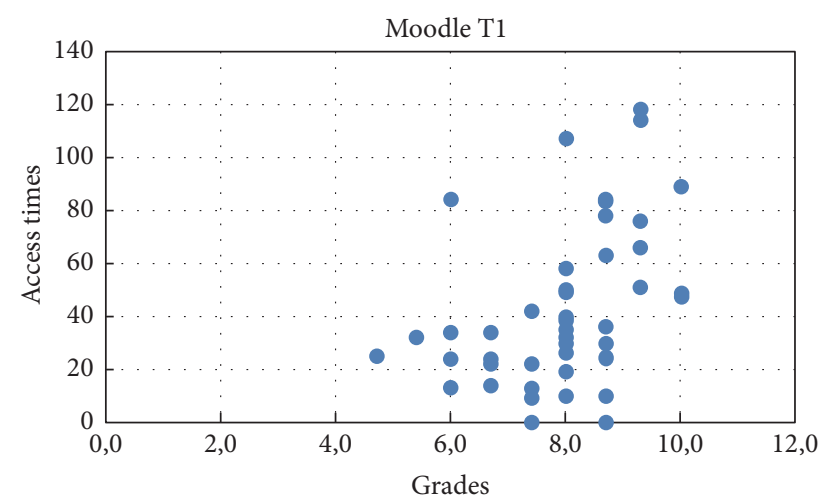

FIGURE 1: Scatter plot showing the amount of hits in relation to the marks obtained in the first test. It may be noticed that the more accessible the digital teaching platform, the greater the marks obtained by the students.

Before the first exam, students accessed Moodle 2017 times and they accessed 752 times for the second test.

The comparison between the groups showed normality and homogeneity of variances for the analysis among accessions (before 1st Test and before 2nd Test), but did not show normal distribution of data on notes (1st and 2nd Tests).

Thus, the paired $t$-test showed statistically significant differences $(p<0.05)$ between the access number before the first test and before the second test, $p<0,001$.

Just as the number of access times, there was also a significant decrease $(p<0.05)$ between students' grades in first test (with median 8.000, first quartile 7.400, and third quartile 8.700) and in the second test (with median 7.400, first quartile 6.600, and third quartile 7.750) (Wilcoxon Test).

The Pearson correlation coefficient showed a moderate correlation to the correlation analysis between the number of access times before the first test and the grade of the first test ( $p=0,003$ e $r=0,40)$, as well as number of access times before the second test and grade of the second test $(p=0,039$ e $r=0,29$ ).

As the test scores declined and the number of access times also declined, the correlation was made between the decrease in the number of access times with decreasing students notes. The Pearson correlation coefficient showed a statistically significant correlation ( $p=0.0747$ and $r=0.610$ ).

The average grade of the whole class generated a result of 7.9 for the first exam. In the second test, students obtained an average score 7.1. At the end of semester they had an average total of 7.6 scores, the minimum average to go to the next period being a score of 5.0 (Figures 1 and 2).

It is possible to observe that students who obtained grades between 9.1 and 10 accessed 610 times, with average access by student 76,25 from a total of 8 undergraduates.

The students who obtained grades between 8.0 and 9.0 accessed 1003 times, with average access by student 40,12 from a total of 25 learners.

It is also possible to realize that students who obtained grades between 4.0 and 6.0 accessed 212 times, with average access by student 35,33 from a total of 6 academics.

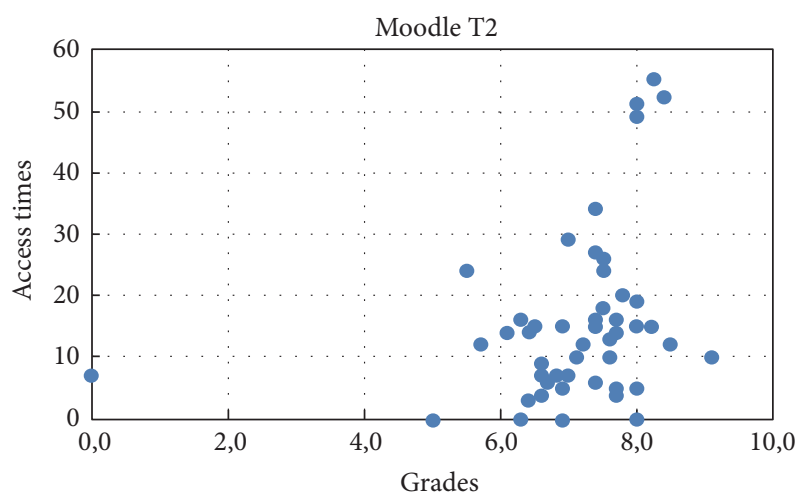

FIgURE 2: Scatter plot showing the amount of hits in relation to the marks obtained in the second test. It can be observed that students who access less a digital teaching platform had a direct influence on their grades.

\section{Discussion}

The education in dental schools needs to evolve to meet the health needs of the population. With this purpose, preparing students to develop a modern dentistry and with high performance in the area requires a rethinking in teaching and research methodology [11].

Our study was the first to analyze statistically the capacity of Moodle platform at the Dentistry graduation in Stomatology Department of São Paulo University. It was observed that access to Moodle platform was associated with improvement of knowledge and higher scores by students $(p<0.05)$ as well as in the Khoo study (2014), when he observed that students of postgraduate degree in pathology, when using the Moodle platform, were able to expand interactive learning experience beyond the classroom setting and to integrate multidisciplinary aspects in the learning of pathology [12].

Digital platform Moodle was able to supply the needs of the students in this study and help them to obtain information about the subject during the entire semester, corroborating with the study conducted by the Dalian Medical University, where 385 dental school students were randomly recruited to complete a questionnaire about the computerized teaching methods and all questionnaires were analyzed. A large portion said the use of computerized methods in teaching is a useful addition to the studies where it can be concluded that computerized teaching methods have the potential to help dentistry undergraduate students [13]. Although our study did not evaluate the importance of digital methods in oral medicine teaching, we can affirm that the virtual platform provides a great material and a supplement for students as an adequate form of study.

The association between regular classes and with a virtual learning environment through Moodle has demonstrated the feasibility to improvements in student performance in stomatology being able to overextend to foreign students of isolated regions where the technology is under development [13].

The development of this study evaluated quantitatively and statistically the direct impact of Moodle in teaching and learning process of the undergraduate students of Bauru 
School of Dentistry, a pioneer in this type of analysis in the field of stomatology and oral medicine, since the search of the current literature was not possible to find textual references.

The digital platform Moodle was associated with better grade for those students who access it for more times and was able to supply the needs of the students and help them to obtain information about the oral medicine. The Moodle allows students to study the content before it is administered in the classroom setting, increasing the yield in practical activities, as well as the weighted mean of the course. To this end, the Moodle material must be dynamic and interactive in order to encourage students to study content that tends not to initially arouse their interest.

\section{Conflicts of Interest}

No competing financial interests exist.

\section{Acknowledgments}

The authors of this study would like to thank CAPES (Coordenação de Aperfeiçoamento de Pessoal de Nível Superior) for their financial support of this study and Janaína Gomes Maciel, Patricia Kerges Bueno, and Laura Bernardo, the monitors that inserted and collected platform data.

\section{References}

[1] J. Cook, “The role of virtual learning environments," LTSN Bioscience Bulletin, 2002.

[2] F. Lau and J. Bates, "A review of e-learning practices for undergraduate medical education," Journal of Medical Systems, vol. 28, no. 1, pp. 71-87, 2004.

[3] M. C. Garbin, S. F. do Amaral, C. O. Mendes, E. Ogasawara, and J. M. Rocha, "Adaptation of the moodle for application in distance education course at the state university of campinas," Procedia - Social and Behavioral Sciences, vol. 46, pp. 2514-2518, 2012.

[4] M. Ketterl, R. Mertens, and O. Vornberger, "Bringing Web 2.0 to web lectures," Interactive Technology and Smart Education, vol. 6, no. 2, pp. 82-96, 2009.

[5] X. J. Qin, J. Kong, L. Lu, Z. F. Lu, and X. K. Wang, "Application of problem-based learning in a large class in stomatology course," Journal of Oral and Maxillofacial Surgery, vol. 68, no. 4, pp. 739743, 2010.

[6] M. M. A. E. Tantawi, "Factors affecting postgraduate dental students' performance in a biostatistics and research design course," Journal of Dental Education, vol. 73, no. 5, pp. 614-623, 2009.

[7] M. M. A. El Tantawi, "Evaluation of a blog used in a dental terminology course for first-year dental students," Journal of Dental Education, vol. 72, no. 6, pp. 725-735, 2008.

[8] R. J. Murphy, S. A. Gray, S. R. Straja, and M. C. Bogert, "Student learning preferences and teaching implications," Journal of dental education, vol. 68, no. 8, pp. 859-866, 2004.

[9] N. S. Ali, K. Hodson-Carlton, and M. Ryan, "Students' perceptions of online learning: implications for teaching." Nurse educator, vol. 29, no. 3, pp. 111-115, 2004.

[10] I. M. Inuwa, M. Al Rawahy, V. Taranikanti, and O. Habbal, "Anatomy "steeplechase" online: Necessity sometimes is the catalyst for innovation," Anatomical Sciences Education, vol. 4, no. 2, pp. 115-118, 2011.

[11] S. A. Kawas, K. S. Fakhruddin, and B. U. Rehman, "A comparative study of oral health attitudes and behavior between dental and medical students: the impact of dental education in United Arab Emirates," Journal of International Dental and Medical Research, vol. 3, no. 1, pp. 6-10, 2010.

[12] U. S. Khoo, "Innovative use of technologies to enhance the teaching of pathology," Pathology, vol. 46, p. S31, 2014.

[13] C. Shi, L. Wang, X. Li et al., "Virtual classroom helps medical education for both Chinese and foreign students," European Journal of Dental Education, vol. 19, no. 4, pp. 217-221, 2015. 


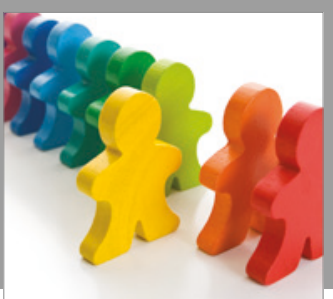

Autism

Research and Treatment
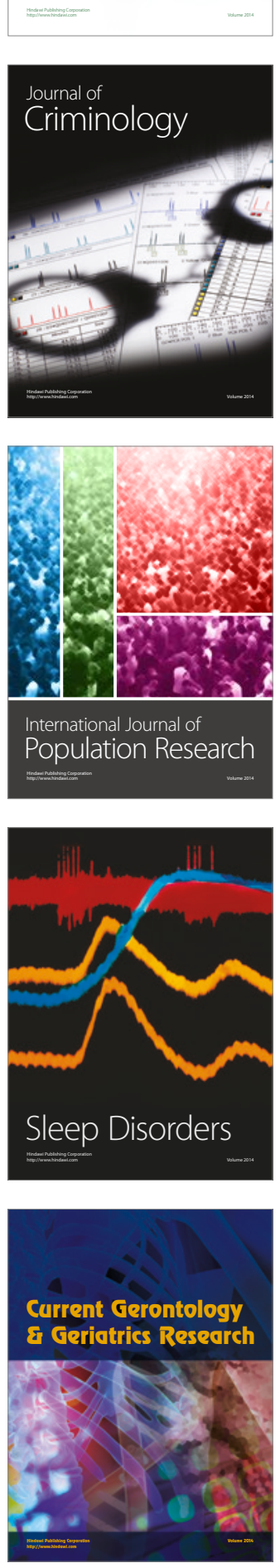

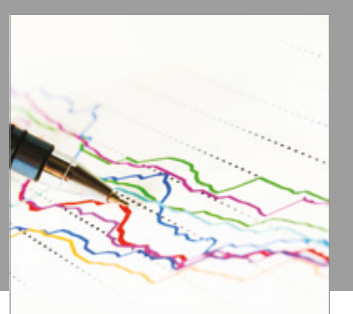

Economics

Research International

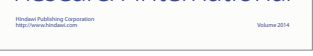

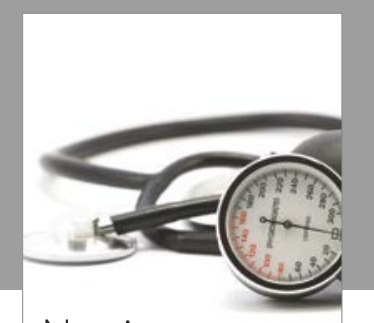

Nursing

Research and Practice

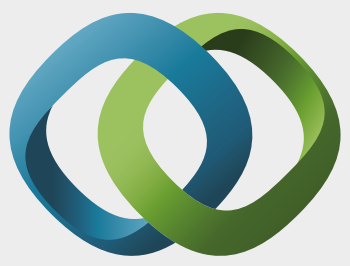

\section{Hindawi}

Submit your manuscripts at

https://www.hindawi.com
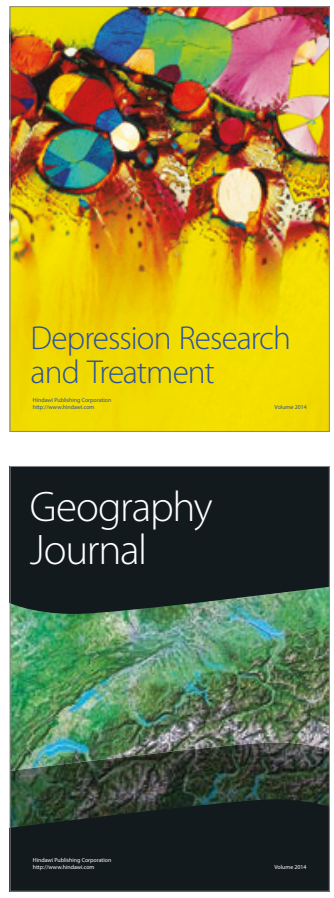
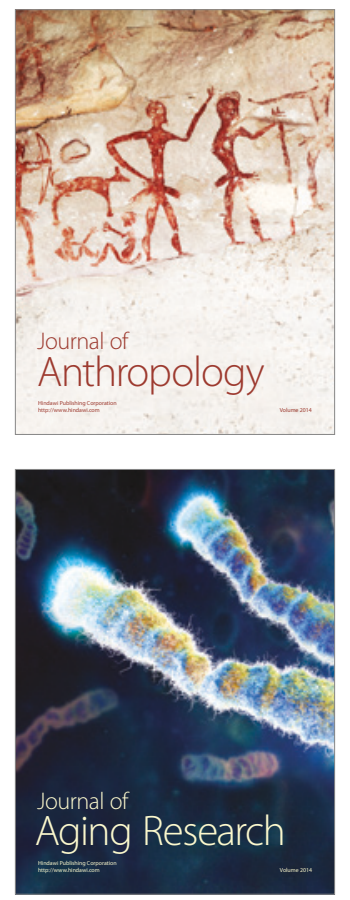
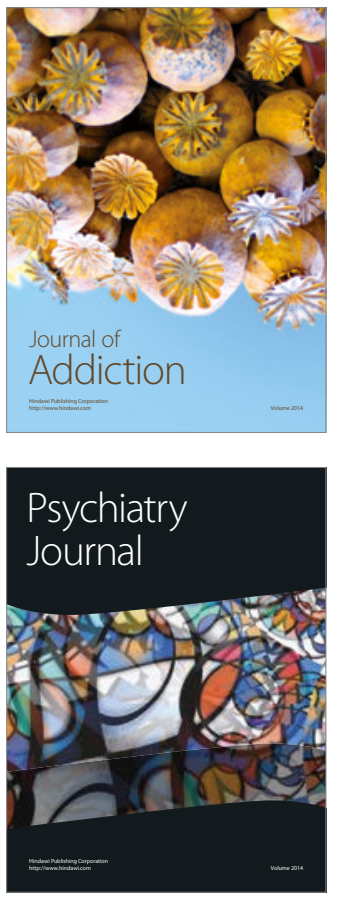

Child Development

Research

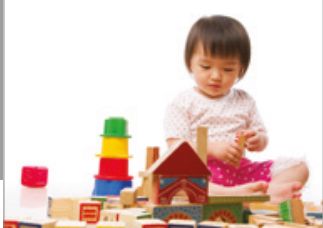

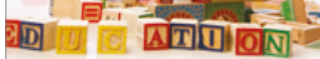
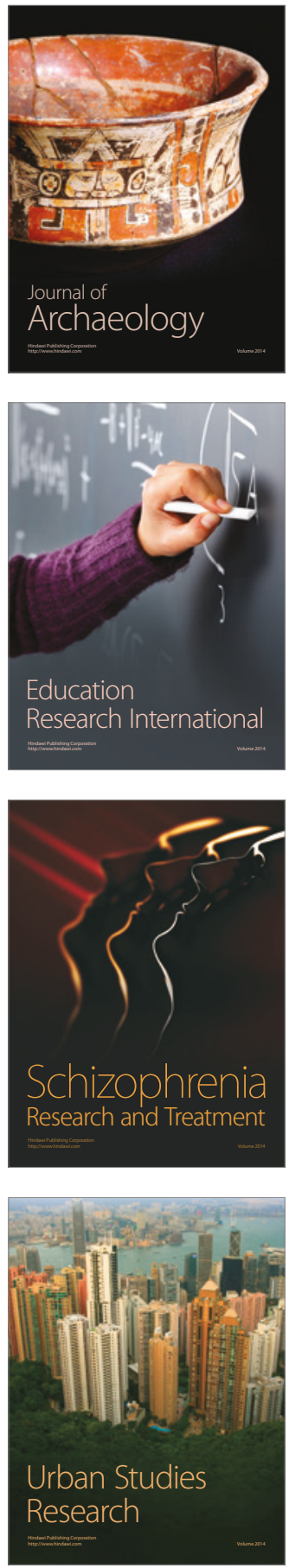